LA-UR-96-709

Viscoelastic Struts for Vibration Mitigation of FORTE'

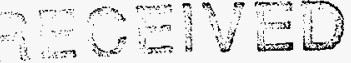

APR 18990

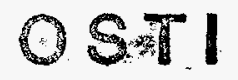

Joseph R: Maley, CSA Engineering Inc.

Thomas Butler, ESA-EA, LANL

SPIE's 1996 Symposium on Smart Structures

and Materials 26 - 29 February, 1996

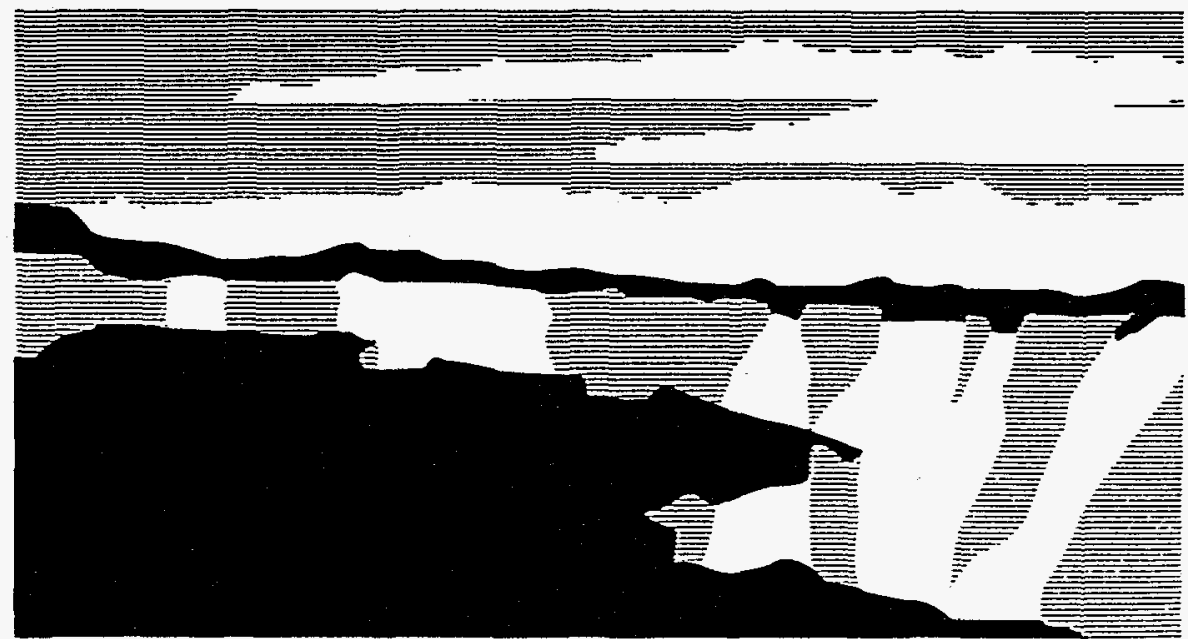

Los Alamos National Laboratory, an affirmative action/equal opponunity emplóyer, is operated by the University of California for the U.S. Department of Energy under contract W-7405-ENG-36. By acceptance of this article, the publisher recognizes that the U.S. Governomet retains a nonexclusive, royalty-free license to

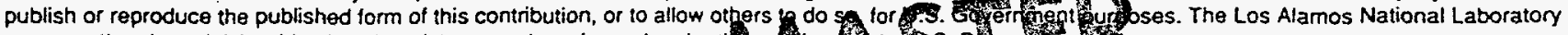

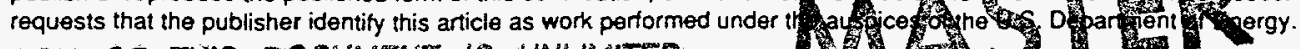




\section{DISCLAIMER}

Portions of this document may be illegible in electronic image products. Images are produced from the best available original document. 


\title{
Viscoelastic struts for vibration mitigation of FORTÉ
}

\author{
Joseph R. Maly \\ CSA Engineering, Inc. \\ Palo Alto, California \\ Thomas A. Butler \\ Los Alamos National Laboratory \\ Los Alamos, New Mexico
}

\begin{abstract}
FORTÉ is a small satellite being developed by Los Alamos National Laboratory (LANL) and Sandia National Laboratories Albuquerque (SNLA). It will be placed into orbit via a Pegasus launch in 1996. Testing a full-scale engineering model of the structure using the proto-qualification, system-level vibration spectrum indicated that acceleration levels caused by structural resonances exceed component levels to which certain sensitive components had previously been qualified. Viscoelastic struts were designed to reduce response levels associated with these resonances by increasing the level of damping in key structural modes of the spacecraft. Four identical shear-lap struts were fabricated and installed between the two primary equipment decks. The struts were designed using a system finite element model (FEM) of the spacecraft, a component FEM of the strut, and measured viscoelastic properties. Direct complex stiffness testing was performed to characterize the frequency-dependent behavior of the struts, and these measured properties (shear modulus and loss factor) were used to represent the struts in the spacecraft model. System-level tests were repeated with the struts installed and the response power spectral densities at critical component locations were reduced by as much as $10 \mathrm{~dB}$ in the frequency range of interest.
\end{abstract}

Key words: viscoelastic material, graphite epoxy, finite element analysis, passive damping, modal strain energy, direct complex stiffness testing

\section{INTRODUCTION}

This paper describes the development of viscoelastic struts that were developed to reduce vibrations of the FORTÉ spacecraft when the structure is subjected to the dynamic loading associated with launch and protoqualification testing. FORTÉ is a small satellite that will be placed in orbit in 1996. The structure weighs approximately $425 \mathrm{lb}$, and is roughly 80 inches high and 40 inches in diameter. It was developed and built by LANL in conjunction with SNLA for the United States Department of Energy. The FORTÉ primary structure, shown in Figure 1, was fabricated primarily with graphite epoxy, using aluminum honeycomb core material for equipment decks and solar panel substrates. Equipment decks were bonded and bolted through aluminum mounting blocks to adjoining structure. In the photograph, the structure is shown in its modal test configuration. It is mounted to the baseplate by a series of flexures similar to those which will mount the satellite to the launch vehicle separation ring.

The FORTÉ schedule from payload conception to launch was very short, and satellite and payload specifications were written before the design was complete. Random vibration testing of the Engineering Model (EM) of the structure showed that acceleration PSDs for critical components on both decks would exceed protoqualification levels, and it became evident that some form of vibration suppression was needed. Figure 2 shows the vertical random vibration proto-qualification level for mid deck payload components with the measured PSD 

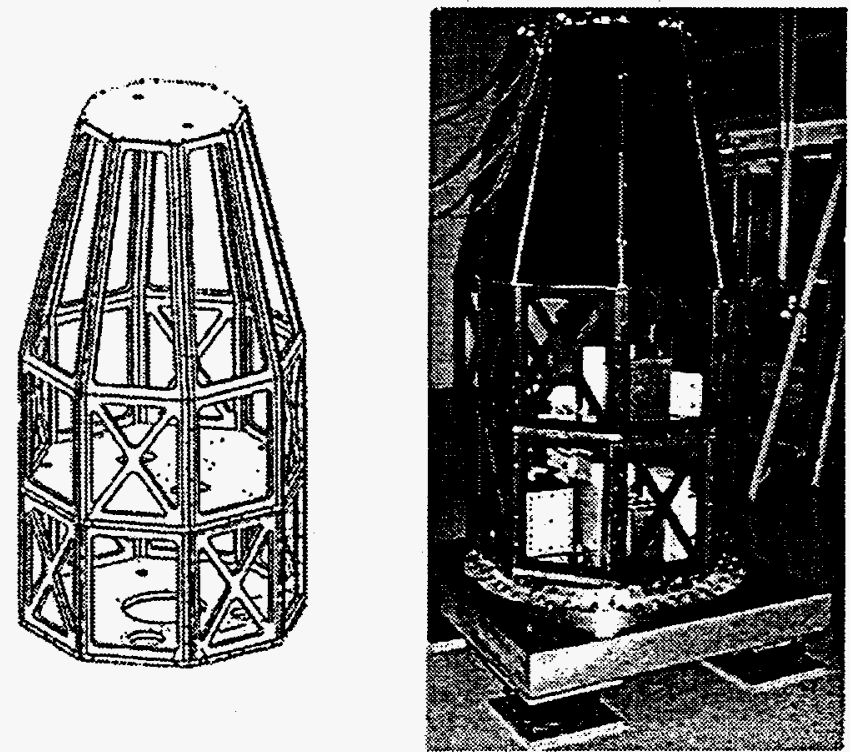

Figure 1: FORTÉ spacecraft structure

for a key component. The structure's design and the FORTÉ equipment layout were virtually complete by this time, so retrofit passive damping treatments were considered in conjunction with force limited random vibration testing. A structural modification was implemented, consisting of high-loss, moderate-stiffness struts installed between the bottom and mid decks of the structure. The struts are shown in Figure 3. Addition of these struts coupled the dynamics of the decks, and shearing of the struts' viscoelastic material (VEM) resulted in dissipation of vibrational energy in an important frequency band and reduction of vibration response at key spacecraft components. The viscoelastic struts were used in conjunction with force limited vibration testing, customized bracketry modified to provide isolation, and manipulation of the system mass distribution, for successful vibration mitigation of FORTÉ.

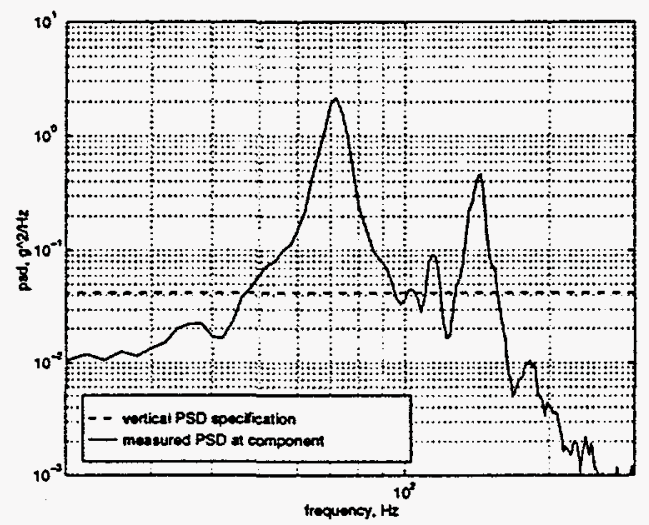

Figure 2: FORTÉ random vibration proto-qualification level and measured PSD 


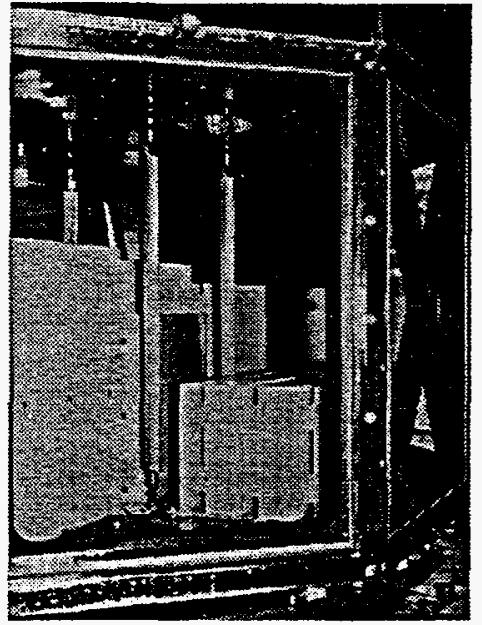

Figure 3: Struts installed between FORTÉ decks

\section{DAMPING ANALYSIS WITH STRUCTURAL MODEL}

A Nastran finite element (FE) model of the FORTÉ structure was used for prediction of system structural response with and without retrofit damping treatments. Boundary conditions consisted of a series of translational springs around the base of the cylindrical structure, representing the flexures on which the structure was mounted on the test stand. These flexures are similar to the mounting of the satellite on the launch vehicle. The model accurately represented global bending and torsion modes, bottom deck and mid deck bending modes, and global plunge modes. Figure 4 shows the predicted shapes for some important modes. Deck modes below $120 \mathrm{~Hz}$ and plunge modes around $170 \mathrm{~Hz}$ were specifically targeted for vibration suppression.
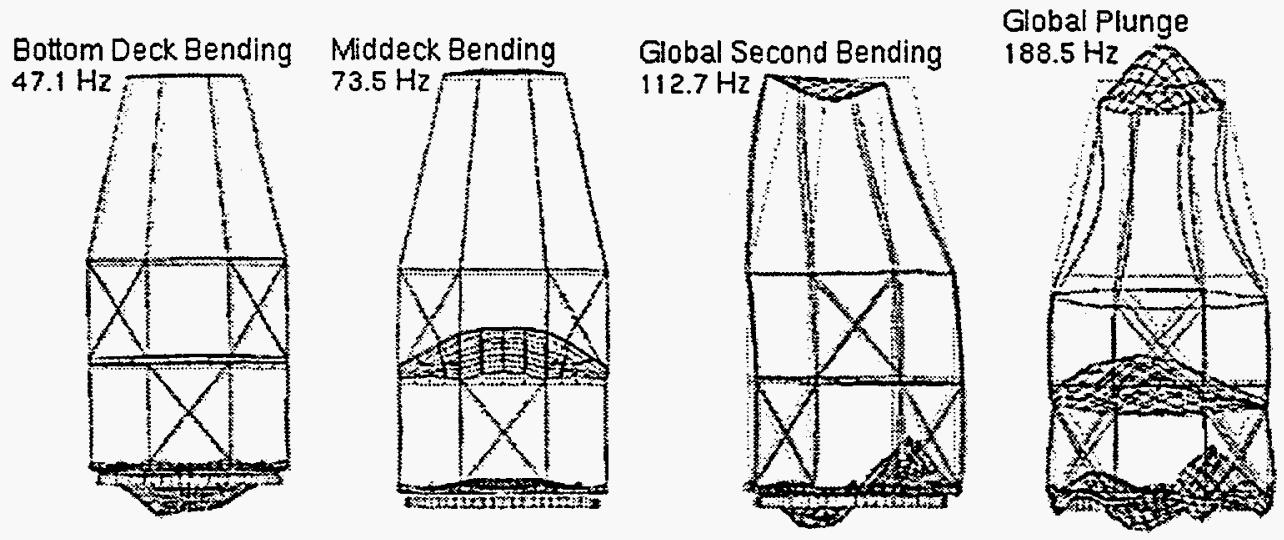

Figure 4: Nastran model predicted mode shapes

Several approaches were considered for implementation of passive damping in the FORTÉ structure, including constrained-layer damping, viscoelastic struts, and viscous struts. Viscoelastic strut configurations and variations of a proposed viscous strut were investigated. Performance predictions were made using the system FE model. 
The system FE model was used to evaluate modal strain energy distribution in the modes that contributed significantly to the response of the payload components. The rationale for using high-loss struts mounted between the bottom deck and mid deck of the satellite is that the strut viscoelastic material is strained in shear due to local deck bending modes as well as global bending, torsion and plunge modes. Equipment on the bottom deck is very closely spaced, restricting placement of the struts, but mounting the struts symmetrically around the antenna can was found to be effective. Strut mounting locations on the bottom deck are shown in Figure 2. System analysis was performed using the Nastran model to predict performance improvements that might be expected with various viscoelastic strut configurations, and variations on a viscous strut that was proposed.

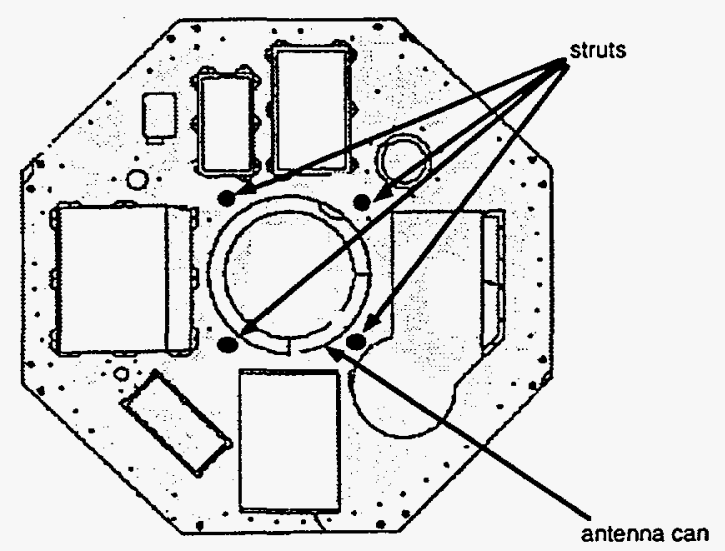

Figure 5: Bottom deck equipment configuration and strut locations

A schematic of the viscoelastic strut configuration is shown in Figure 6. Early models of this strut concept used estimates of stiffness and loss from hand calculations based on experience with VEMs. A refined component-level FE model of the strut, shown in Figure 7, included springs to account for compliance in the strut end fittings, and was tuned to results from component-level direct complex stiffness testing described in Section 4 of this paper. The tuned component FE model of the strut was then modified to investigate different strut configurations, with variations on the VEM thickness and VEM shear area.

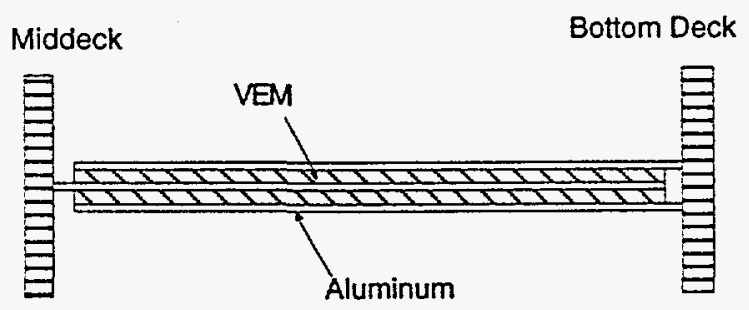

Figure 6: Schematic of viscoelastic strut configuration

For each strut configuration of interest, the component FE model was exercised to compute strut stiffness and strut loss versus frequency. These functions were then used to model the struts in the system FE model, as beam elements having the appropriate frequency-dependent stiffness and loss characteristics. Nastran provides for the frequency dependent material behavior in random response analysis, so the FORTÉ system model was subjected to the proto-qualification random vibration inputs, with the struts installed in the model, and response predictions were computed for comparison with baseline response and other strut designs. 


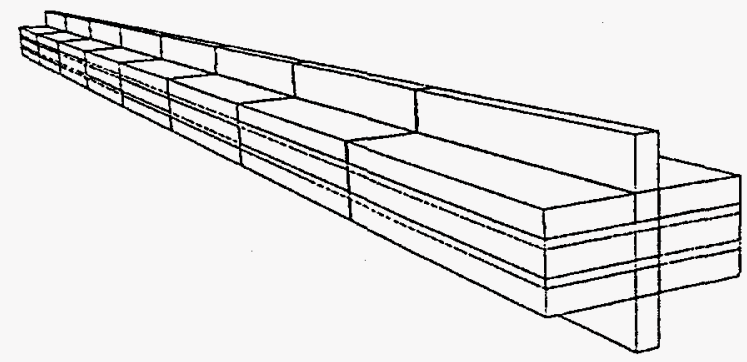

Figure 7: Finite element model of viscoelastic strut

Viscous struts were modeled as beam elements in parallel with viscous dashpots. Stiffness of $54 \mathrm{lb} /$ in and damping of $4.4 \mathrm{lb}-\mathrm{sec} /$ in were included as specified by the strut vendor. Struts with other dashpot constants ranging from 0.8 to $110 \mathrm{lb}$-sec/in were also analyzed.

Table 1 gives RMS response predictions, in g's, for various strut designs, subjected to the vertical protoqualification-level random vibration input. Both the viscous and viscoelastic struts were found to produce favorable results, so selection of the appropriate treatment was based on fabrication and in-service concerns. Ultimately, the viscoelastic struts were preferred because of the simplicity of fabrication and LANL's reluctance to include viscous fluids in a spacecraft application.

\begin{tabular}{|c|c|c|c|c|c|c|c|c|}
\hline \multirow[b]{4}{*}{ input } & \multirow[b]{3}{*}{ baseline } & \multirow{2}{*}{\multicolumn{3}{|c|}{$\begin{array}{c}\text { viscoelastic struts } \\
\text { loss }=.3 \\
\text { strut stifiness, lb } / \text { in }\end{array}$}} & \multicolumn{4}{|c|}{$\begin{array}{c}\text { viscous struts } \\
\text { stlffness }=54 \mathrm{lb} / \text { in }\end{array}$} \\
\hline & & & & & strut d & ping & efficien & $2.5 /$ in \\
\hline & & 50000 & 30000 & 10000 & 0.88 & 4.4 & 22.0 & 110.0 \\
\hline & 1.55 & 1.55 & 1.55 & 1.55 & 1.55 & 1.55 & 1.55 & 1.55 \\
\hline center of mid deck & 7.69 & 4.01 & 3.74 & 4.60 & 6.29 & 4.30 & 3.15 & 3.79 \\
\hline scan wheel. inner & 6.76 & 3.30 & 3.08 & 3.87 & 5.71 & 3.81 & 2.74 & 3.40 \\
\hline scan wheel, outer & 5.33 & 2.53 & 2.32 & 2.92 & 4.53 & 2.97 & 2.33 & 3.38 \\
\hline corner of mid deck & 4.23 & 3.70 & 3.59 & 4.04 & 3.81 & 3.69 & 3.42 & 3.26 \\
\hline corner of antenna can & 2.28 & 3.00 & 2.55 & 2.87 & 2.16 & 1.94 & 2.26 & 3.51 \\
\hline corner lower deck & 2.17 & 1.97 & 1.92 & 2.10 & 2.34 & 2.26 & 2.11 & 2.06 \\
\hline
\end{tabular}

Table 1: Predicted responses, RMS g's to $300 \mathrm{~Hz}$, to vertical random vibration

\section{STRUT DEVELOPMENT AND MATERIAL TESTING}

As described above, trade studies were performed with the FE model to determine the appropriate stiffness and loss characteristics of the struts. Analytical predictions of strut stiffness and loss were correlated with direct complex stiffness test results from an initial design of the strut that was fabricated and tested. The figures of merit for optimization of the design were (1) RMS response at the sensitive equipment locations and (2) reduction of peak response levels to the specification level to which they were tested, i.e., $0.042 \mathrm{~g}^{2} / \mathrm{Hz}$.

Four damped struts plus one spare were built. The viscoelastic material, 3M 9473 pressure-sensitive adhesive, was configured with a thickness of 0.040 inches, and a shear area of about 18 square inches. Attachment to the bottom and mid decks of the structure was achieved with 10-32 threaded inserts in the decks. The end fittings of each strut were configured to provide a turn-buckle mechanism for installation of the struts. It should be noted that any compliance in the struts at the deck-attachment locations works against the function of the struts. 
An important challenge in this design was to minimize the compliance of the strut end fittings. Figure 8 shows a closeup of the strut attachment at the FORTÉ mid deck. Material testing was performed to quantify the mechanical properties and outgassing characteristics.

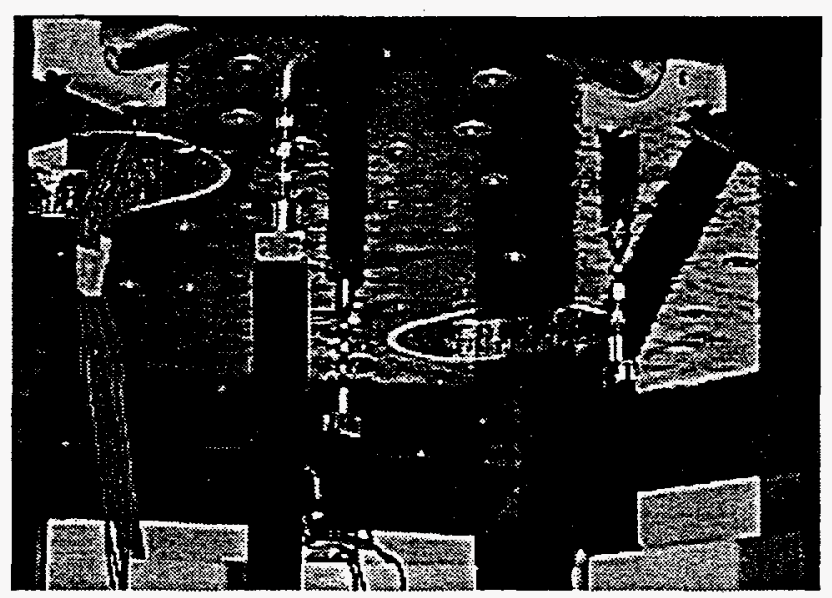

Figure 8: Strut attachment at FORTÉ mid deck

Material testing - mechanical properties. The FORTÉ temperature environment is benign, since both launch and testing environments are thermally controlled, so temperature variation is not an issue. But knowledge of the viscoelastic properties as functions of frequency was critical to development of the struts. The material was tested, and the temperature-frequency nomogram that describes the relevant mechanical properties, shear modulus and loss factor, is shown in Figure 9. This nomogram conveys information about the material's shear modulus and loss factor as functions of temperature $\left(-25^{\circ} \mathrm{F}\right.$ to $185^{\circ} \mathrm{F}$ ) and frequency (to $600 \mathrm{~Hz}$ ). Isotherms of shear modulus and loss factor for the FORTÉ strut material at $70^{\circ} \mathrm{F}$, are plotted versus frequency in Figure 10.

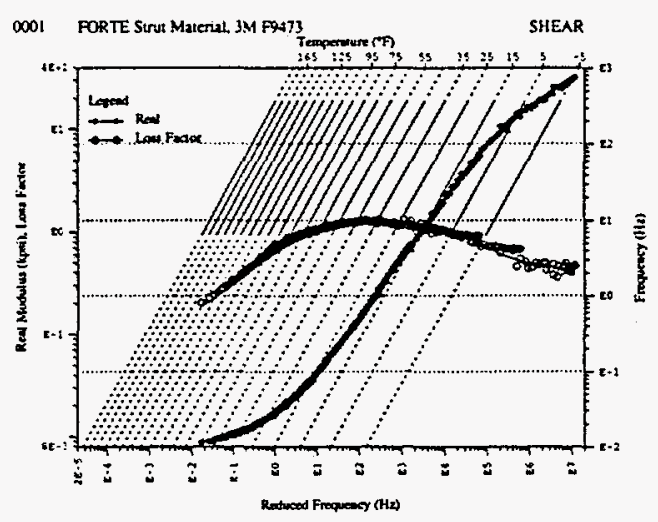

Figure 9: Temperature-frequency nomogram for FORTÉ viscoelastic material

Material testing - outgassing. Outgassing was not considered a major issue for the FORTÉ spacecraft, but for completeness, and to insure that this did not become an issue at some point in the future, the selected material was characterized for outgassing, in accordance with ASTM E-595 and NASA SP-R-0022A specifications. The total mass loss (TML) was measured at $0.68 \%$, and the collected volatile condensible material (CVCM) was $0.03 \%$. The NASA standards for acceptable spacecraft materials are TML of $1.00 \%$, and CVCM is $0.10 \%$. 


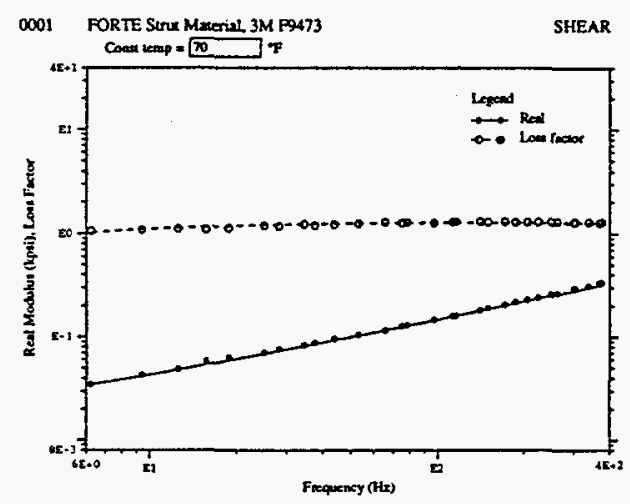

Figure 10: Isotherms of FORTÉ viscoelastic material properties at $70^{\circ} \mathrm{F}$

\section{DIRECT COMPLEX STIFFNESS TESTING OF STRUTS}

Stiffness and loss of the FORTÉ struts were measured by means of a test procedure referred to as direct complex stiffness testing. The test rig consisted of virtually rigid "book ends" (mounting brackets to support the strut under test) bolted to a large work plate, and a hydraulic shaker positioned to excite the strut axially. A strain-gage-type load cell was mounted in series with the strut. A schematic of the test configuration is shown in Figure 11. The strut was excited axially with a controlled random force, and axial displacement was measured
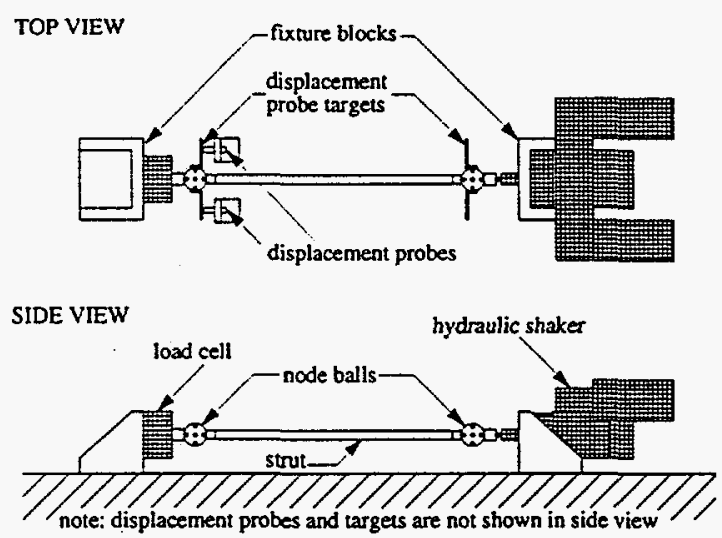

Figure 11: Schematic of strut test configuration

with eddy current probes referencing the angle-bracket "flags" attached to each node ball. Complex stiffness was calculated by dividing the input force by the measured displacement. Measured stiffness functions are shown in Figures 12 for input force levels of $100 \mathrm{lbf}, 200 \mathrm{lbf}$, and $300 \mathrm{lbf}$. Measured strut loss versus frequency is shown in Figure 13. 


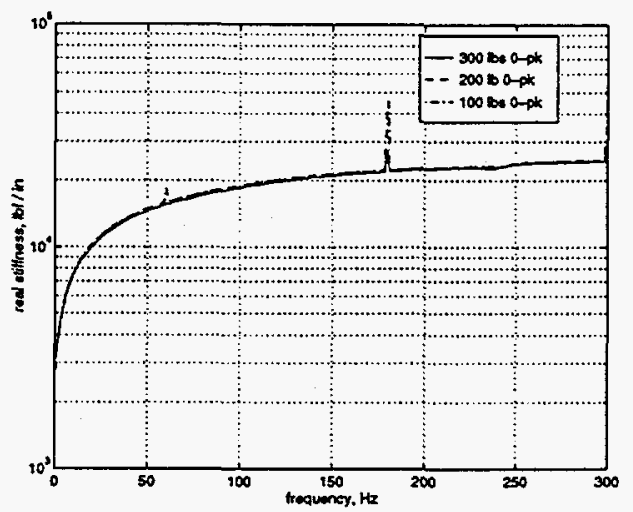

Figure 12: Measured strut stiffness versus frequency

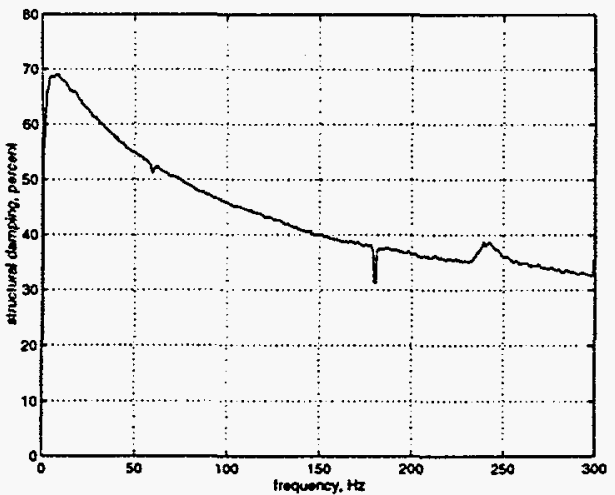

Figure 13: Measured strut loss versus frequency

\section{RANDOM VIBRATION TESTS}

Random vibration testing was performed as part of the proto-qualification testing for FORTÉ. The figures of merit for vibration mitigation design were based on measured responses when the structure is subjected to random vibration testing: (1) minimization of RMS responses at sensitive equipment, and (2) reduction of peak responses to $0.042 \mathrm{~g}^{2} / \mathrm{Hz}$, the level to which equipment was tested. It was especially important to reduce peak levels below $0.042 \mathrm{~g}^{2} / \mathrm{Hz}$ in frequency bands where component resonances were present.

Figures 15 through 17 present comparison plots of PSD response at key locations on the structure with and without the viscoelastic struts. Figure 14 shows responses at the scan wheel, a very important payload component. The reduction of 3 orders of magnitude around $70 \mathrm{~Hz}$ shown in this plot was especially significant, because this component is known to have an internal resonance around $65 \mathrm{~Hz}$. Response levels above $100 \mathrm{~Hz}$ for the scan wheel were reduced with force limited testing. Figure 15 shows responses at the corner of the antenna can on the bottom deck. Figure 16 shows responses at the corner of the mid deck and Figure 17 gives responses at the center of the mid deck. 


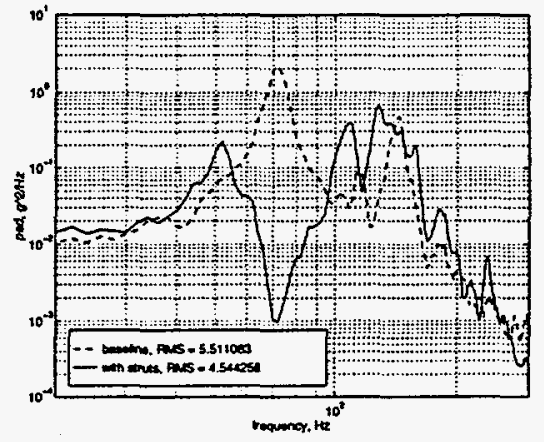

Figure 14: Random vibration response at scan wheel

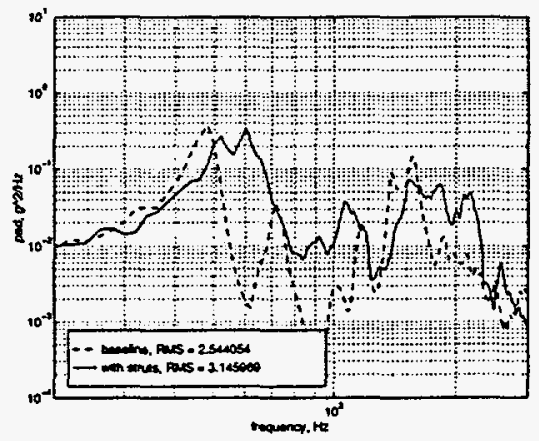

Figure 15: Random vibration response at corner of antenna can

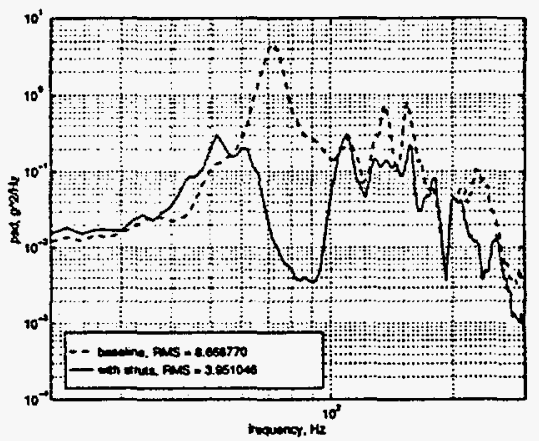

Figure 16: Random vibration response at corner of mid deck

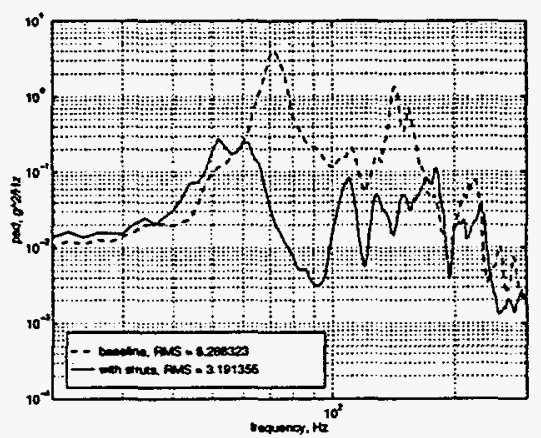

Figure 17: Random vibration response at center of mid deck 


\section{SUMMARY}

Viscoelastic struts were designed, built, and tested as part of a program to reduce vibrations of the FORTÉ spacecraft. The technical objective of the work was reduction of response at the location of payload components when the structure is subjected to the dynamic loading associated with launch and proto-qualification testing. A Nastran finite element model of the FORTÉ structure was used for system analysis and damping design. Analytical trade studies were performed and strut FE model was built to determine the best design configuration for a viscoelastic strut. Material testing and direct complex stiffness testing of the struts were performed. Addition of the viscoelastic struts coupled the dynamics of the decks, and shearing of the viscoelastic material resulted in dissipation of vibrational energy in an important frequency band and reduction of vibration response at key spacecraft components. The viscoelastic struts were used in conjunction with force limited vibration testing, customized bracketry modified to provide isolation, and manipulation of the system mass distribution, for successful vibration mitigation of FORTE.

\section{Acknowledgment}

The authors would like to acknowledge Jim Lake of the testing group at Los Alamos for performing the vibration tests and for aiding in data interpretation. The help of Steve Knox and Steve Wallin from the FORTÉ project office in providing the funding, motivation, and time to perform this work is also acknowledged.

\section{REFERENCES}

[1] Butler, T. A., "Testing Experience with the FORTÉ Small Satellite," 16th Aerospace Testing Seminar Proceedings, sponsored by the Aerospace Corporation and the Institute of Environmental Sciences, Manhattan Beach, California, March 12-14, 1996.

[2] Scharton, T. D., "Vibration-Test Force Limits Derived from Frequency-Shift Method," Journal of Spacecraft and Rockets, Vol. 32, No. 2, pp. 312-316, 1995.

[3] Johnson, C. D., Kienholz, D. A., "Prediction of Damping in Structures with Viscoelastic Materials," MSC/NASTRAN User's Conference Proceedings, March 1983.

\section{DISCLAIMER}

This report was prepared as an account of work sponsored by an agency of the United States Government. Neither the United States Government nor any agency thereof, nor any of their employees, makes any warranty, express or implied, or assumes any legal liability or responsibility for the accuracy, completeness, or usefulness of any information, apparatus, product, or process disclosed, or represents that its use would not infringe privately owned rights. Reference herein to any specific commercial product, process, or service by trade name, trademark, manufacturer, or otherwise does not necessarily constitute or imply its endorsement, recommendation, or favoring by the United States Government or any agency thereof. The views and opinions of authors expressed herein do not necessarily state or reflect those of the United States Government or any agency thereof. 